NBSIR 76-1096

\title{
Guidelines for the Determination and Development of Generic Safety Standards
}

Robert G. Hendrickson

Institute for Applied Technology

National Bureau of Standards

Washington, D. C. 20234

June 1976

Final

Issued August 1976

Prepared for

Consumer Product Safety Commission

5401 Westbard Avenue

- thesda, Maryland 20207

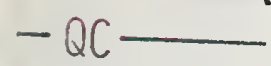

100

.456

$76-1096$

1976 


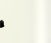

. 


\section{GUIDELINES FOR THE DETERMINATION AND DEVELOPMENT OF GENERIC SAFETY STANDARDS}

OCT 251982

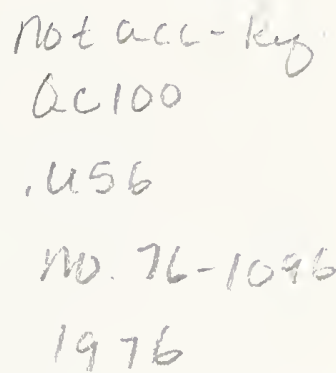

Robert G. Hendrickson

Institute for Applied Technology

National Bureau of Standards

Washington, D. C. 20234

June 1976

Final

Issued August 1976

Prepared for

Consumer Product Safety Commission

5401 Westbard Avenue

Bethesda, Maryland 20207

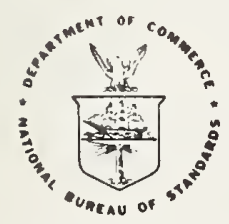

U.S. DEPARTMENT OF COMMERCE, Elliot L. Richardson, Secretary Edward O. Vetter, Under Secretary

Dr. Betsy Ancker-Johnson, Assistant Secretary for Science and Technology

NATIONAL BUREAU OF STANDARDS, Ernest Ambler, Acting Director 

Chapter I. Foundations and Background.................... I-I

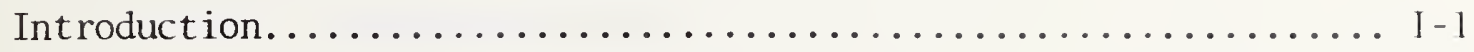

A. What Is A Generic Standard?...................... I-2

B. Principal Elements of Generic Safety Standards............. I-2

C. Hazard, Risk, Exposure, Accident and Contro1............ I-6

D. Process of Generic Standard Development................ I-7

E. Organization of the Guidelines.................... I-8

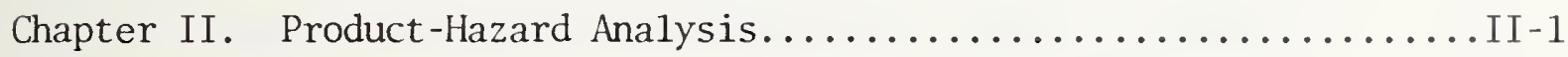

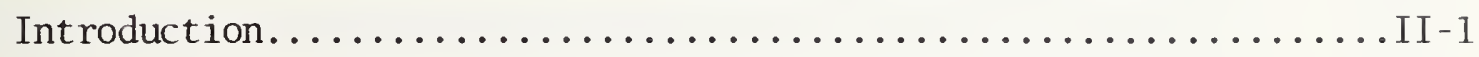

A. Principal Factors in the Analysis of Product-Hazard Characteristics..................................

B. Combinations of Principal Factors..................... II

C. Procedure for the Determination of the Generic Case........... II-5

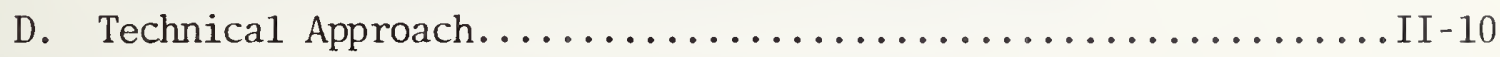

Introduction...............................

1. Injury Severity Analysis and Classification.............II-11

1.1. Injury Types...........................

1.2. Tabulations of Product-Severity Data.............. II-12

1.3. Injury Severity and the CPSA................. II 13

2. Product Characteristics......................... II

Introduction............................ 14

2.1. Product Involvement...................... II 14

2.2. Product Safety Requirements..................II-15

2.3. Product Functional Performance................. II-16 

3. Classification of Hazard....................... II 17

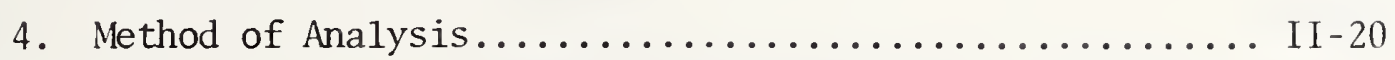

4.1. Assignment Criteria.................... II-22

4.2. Identifying the Countermeasure............. II -23

4.3. Characterizing the Test Method............. II-24

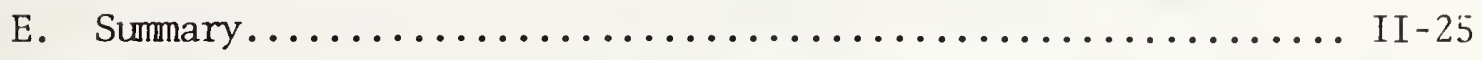

Chapter III. Developing the Generic Standard...................III-1

Introduction................................

A. Product Characteristics Modified by Generic Standard.........III-1

B. Hazard Characteristics Controlled by Generic Standard........III-1

C. Countermeasure and Test Methods..................... III-2

D. Form of the Standard..............................

E. Content of the Standard............................

F. Generic Standards and the Process of Development..........III-3

Chapter IV. Impact Evaluation of Generic Standard............ IV-1

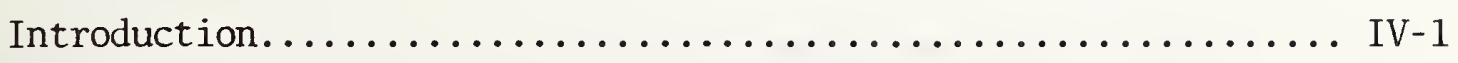

A. Technological Impacts........................ IV-1

B. Cost-Benefit................................. IV

C. Estimate of Hazard or Injury Reduction............... IV-3

D. Other Factors in Impact Analysis................. IV-4

Appendix. The Elements of Fault-Tree Analysis................ A-1

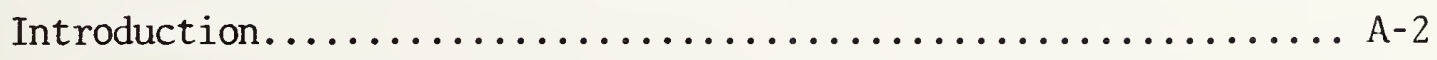

1. Fault-Tree Analysis........................... A-2

2. Fault-Tree Logic........................... A-4

3. Example of Fault-Tree Diagram.................... A-6

4. Benefits of Fault-Tree Analysis.................... A-8 
Figures

I-1 Factors in Standards Development................. I-3

II-1 Flow Chart of Analytic Procedure.................

II-2A Severity Tabulation Matrix...................... 12

II-2B Severity Tabulation Matrix.................... II

II-3 Product Involvement Scoring Matrix................ II-15

II-4 Product Safety Scoring Matrix.................. II-16

II-5 Product Performance Scoring Matrix............... II-17

II-6 Generic Standard Development................. II-21

A-1 Example, Fault-Tree Diagram.................. A-6

Tables

II-1 Array of Combinations of Principal Factors............II-4

II-2 Sumnary of Methods and Data Sources............... II-10

II-3 Hazard Type Classifiers..................... II 18

II-4 Classification of Factors in Hazard Creation.......... II-19

IV-1 Cost-Benefit Array........................ 


\section{ABSTRACT}

These guidelines were prepared to assist the CPSC in the development of generic safety standards. This development is based on conceptual models of product-hazard interactions and analyses of accident sequences, product clustering, and hazard characteristics.

The motivation for these guidelines is based on a perceived need to evolve generic standards instead of manifold product-specific standards; to expedite the standard development process; and to enhance the efficiency of standards for consumer product safety. 

CHAPTER 1. FOUNDATIONS AND BACKGROUND

Introduction

These guidelines have been prepared for the purpose of assisting in the analysis, development and evaluation of generic safety standards. They provide a systematic approach to the investigation of product-hazard problems, starting with the principal factors to be analyzed and ending with a discussion of likely changes in the traditional process of standards development.

A generic safety standard is associated with a large number of consumer product-types. The scope of a generic standard is in direct contrast with a product-specific standard, which addresses the control of a single product or product-type. The ideal generic standard has a single test method for a11 products intended to be covered by the standard. The success, however, and also the greatest challenge, of a generic standard lies in its capability to address a variety of product-types and yet retain sufficient clarity and specificity to be an effective instrument of regulation.

In these guidelines, the development of a generic standard is based on a multi-stage analysis which begins with product-accident data and ends with an identification of a countermeasure, or countermeasures, and a test-method for compliance. Generic standards may also arise from the need to streamline and consolidate a number of extant standards which address a common problem; or may evolve from a need to synthesize portions of extant standards which are similar or related and would be more effective or efficient if restated under a new, single generic standard. 
A. What Is A Generic Standard?

The basic elements of a standard address product identification, which includes descriptions, classifications, sizes and tolerances; references and definitions; safety specifications, which include requirements as they pertain to materials, design, construction, physical attributes, and environment; functional performance; test procedures; quality control; product 1imitations; and exceptions to the standard.

A generic safety standard addresses all of these elements and is obligated to provide the same degree of quality and integrity as any other standard. Although a generic safety standard covers a large number of products or product-types as opposed to the product-specific standard, it must provide an adequate and workable equivalent of each part of a product-specific standard. This is true for several reasons:

(1) The countermeasure must be clearly defined in order that it may be applied to each product-type covered by the standard,

(2) The test method, or methods, must be clearly identified as to the product-types for which they are applicable,

(3) All criteria and special requirements must be unambiguous,

(4) Interpretation and application of the standard must be clear and direct, and

(5) The user must feel secure that the generic standard is as effective as the product-specific standards it displaces.

B. Principal Factors of Generic Safety Standards

In order to understand the nature of a generic safety standard more systematically, we examine in this section a general overview of the

\footnotetext{
*A countermeasure is defined as a means, device, or expedient to counter, modify or rectify a potential hazard.
} 
process for determining the generic situation. Chapters II and III claborate and explicate this process in greater detail. It is our intent here only to explore the general nature of the factors as they relate to the analysis of product-hazard problems.

If an analysis of accident data shows that a large number of products are associated with a common hazard, and the hazard produces approximately the same type and severity of injury under similar environmental conditions, then a generic situation probably exists and it is likely that a countermeasure to the hazard can be specified. The principal factors involved in making an assessment of a generic case are given in Figure I-1.

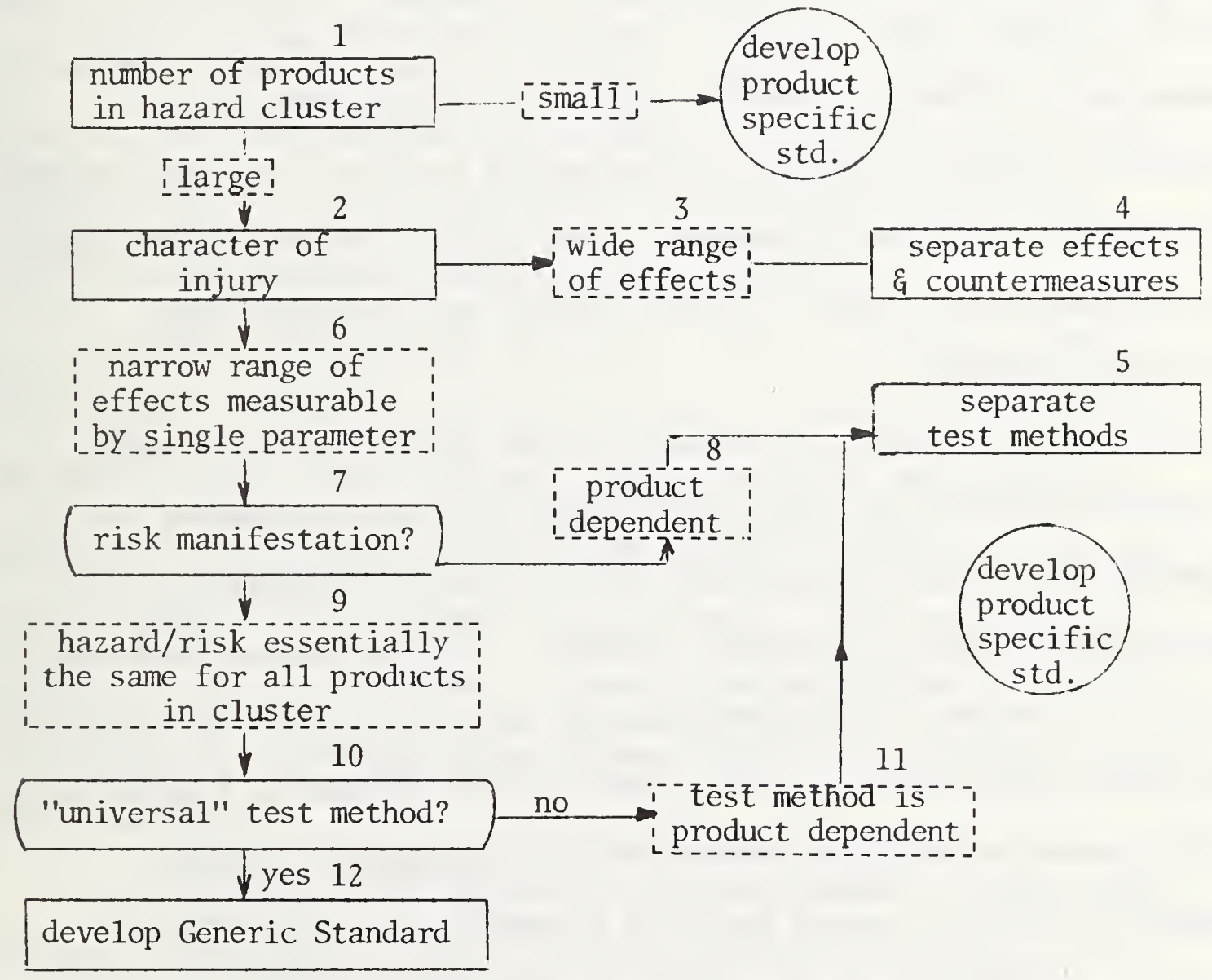

Figure I-1: Factors in Standards Development 
Figure I-1 depicts the major factors that are involved in deciding between a generic or product-specific standard. Box 1 addresses the number of products associated with an identified hazard. If this number is relatively small (without defining what "small" is), it may be desirable to treat the problem on an individual product basis, thereby precluding a generic approach. If, however, the number of products or product-types is relatively large (i.e., great enough to achieve an expected efficiency in preparation time and scope of coverage) we proceed to Box 2. Box 2 addresses the character of the injury associated with the hazard. If the injury occurs with a wide range of effects (Box 3), it may be necessary to measure these effects in different ways. This may require, in the worst case, as many countermeasures as there are diverse effects. The consequence of this is the need to provide a separate test method for each required countermeasure (Boxes 4 and 5). This logic, therefore, leads to the conclusion that productspecific regulation may be the only satisfactory way to address this product-hazard problem.

If, on the other hand, the character of the injury (Box 2) is slight in its range of effects and can be represented by a single parameter, or by a manageable set of related parameters (Box 6), then the regulation of the hazard by generic means has greater likelihood. The next factor which bears directly on our analysis is the determination of how the hazard is manifested in each product-type (Box 7). If the level of risk--defined as a probability of injury--cannot be described independently of the specific product characteristics (Box 8), we may find that a generic description of the risk cannot be made for the entire cluster of products. If this occurs, then 
we are forced into the situation that leads back to the need for separate test methods (Box 5). If, however, the risk is essentially the same for all products in the cluster (Box 9), the generic property is not lost and, in principle, a single countermeasure can be determined. All that remains is to determine the feasibility of a single, universal test method (Box 10). If this is not possible, and technological development of a universal test method is not feasible, then we must rely on test methods which are product-specific (Box 11). It is not necessarily true that this would preclude a generic approach to the problem, however. If the number of test methods needed is equal to the number of producttypes in the cluster, then we are forced back to the logic of Box 5 if the number of types is large. Otherwise, a generic concept is still feasible, even with multiple test methods. The ideal realization is to obtain a universal test method which would provide the basis for a succinct and comprehensive generic standard (Box 12).

In summary, we find that the factors are: (1) that the number of products associated with a hazard is large, (2) that the character of the injury shows a narrow range of effects which are depictable by a single or few descriptors, (3) that the hazard is essentially the same for all products in the cluster, and (4) that a single test method is available or can be developed. A generic standard becomes a reasonable alternative for regulating product-hazard combinations satisfying these four conditions.

A consequence of this approach is the requirement to collect and evaluate information on all the products which may be covered by the standard, and to determine for each product-type the perceived hazard, 
injury severity, countermeasure, and the most efficient test method. The data are needed to ascertain the nature of the product-hazard relationship; and the selection of product-types as candidates for regulation is based on repeated and increasingly refined evaluations of product-hazard characteristics. C. Definitions of Hazard, Risk, Exposure, Accident and Control Definitions

In order to understand the concepts and analysis contained in these guidelines, and to clarify arguments and necessary conditions for the development of generic standards, we introduce working definitions of

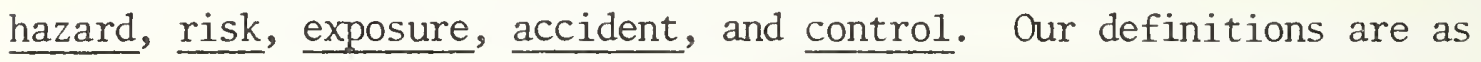
follows :

(1) hazard--a direct or indirect source of injury or damage,

(2) risk--a probability of injury or damage,

(3) exposurea subjection to an action or event,

(4) accident--an event which results in injury or damage,

(5) contro1--a restraint on or influence over a hazard or risk.

As a source of danger a hazard is usually directly related to a form of energy. The form may be mechanical, electrical, thermal, chemical, electromagnetic, radiative, or auditory.

Risk is sometimes equated to hazard, but we assume risk to be related to the control of the hazard and the use of the product.

Exposure is a variable which has been the subject of extensive analyses in a variety of safety problems. Each analysis has tended to define exposure in a way that is amenable to quantification but still retains enough generality to cover a wide range of interpretations. 
The major difficulty in measuring exposure lies in its dependence upon unpredictable causal factors and interactions. It is difficult to define the point at which exposure ends and the process of an accident begins.

An evaluation of accident causation is made difficult because if the evaluation is to be useful in making decisions about product safety, it should include human factors, environmental conditions and product characteristics in scenarios which reflect the likely combinations that may occur.

The definition of control includes not only the substantive restraint of a hazard, but also those controls which are derived from the use of the product and the perceived respect for the risk.

Since these five variables, to which are attached specific definitions, can take a variety of forms, the job of analysis is difficult; but if an approximation to their phenomena is possible, and in many cases it is, conclusions can be drawn which provide the basis for developing a generic or product-specific regulation.

D. Process of Generic Standard Development

The development of a voluntary product-specific standard has traditionally included about seven major factors:

1. number and expertise of participants,

2. orientation to the standard to be developed,

3. trade-offs or negotiations among interested parties,

4. study of affected or related existing standards,

5. problems of liability,

6. data collection,

7. consensus process for approval. 
How are these factors changed if our standard is now generic instead of product-specific? First, the number of participants will be greater, and certainly each product-type should be represented, as a minimum. Second, each member of the group developing the standard must think in terms of generic coverage rather than product-specific coverage. Third, negotiations on countermeasures and a test method may be far more difficult for many product-types than for a single product. Fourth, the displacement of existing standards may be unprecedented in the experience of the members; therefore, care must be taken to ensure the quality and integrity of the generic standard vis-a-vis the standards it replaces. Fifth, it is unlikely that addressing liability will be markedly different from present procedures. Sixth, data collection becomes more extensive and more difficult for purposes of decision making within the comittee on product-hazard inferences, countermeasures, and test methods. And Seventh, the consensus process will be affected because of the potential impact of the standard on greater segments of industry. Chapter III, F, discusses these issues in greater detail, but it is critical that a thorough analysis of product-hazard factors be carried out in order to provide a clear portrayal of the hazard and its countermeasure.

E. Organization of the Guidelines

These guidelines are organized into four functional areas: the structures needed for the analysis and evaluation of product-hazard problems (Chapter II); the methodology needed to develop a generic standard (Chapter III); a summary of items for consideration in an impact evaluation (Chapter IV); and a summary of the elements of fault-tree analysis (Appendix). 
CHAPTER II. PRODUCT-HAZARD ANALYSIS

Introduction

Chapter I presented a general outline for product-hazard analysis as a first step toward a systematic, empirical investigation of product safety.

In this chapter these concepts are developed into an analytic procedure for identifying generic properties in product-hazard combinations. Methods for tabulating data and developing decision information are presented for each phase of the procedure.

The following sections identify the principal factors in the analysis of product-hazard characteristics, examine the regulatory form of each combination of the principal factors, examine the phases for the determination of properties of product-hazard characteristics which are amenable to generic control, and review methods and data sources associated with each phase of the investigation. Taken as a whole, the contents of these sections constitute a procedure for studying a variety of problems associated with hazards, safety, controls, and data development.

A. Principal Factors in the Analysis of Product-Hazard Characteristics

Product-hazard characteristics tend to be associated, primarily, with four basic factors of accident phenomena: injury types, injury severity, morbidity parameters, and product involvement.

Injury type is described by a general class label such as laceration, burn, fracture, contusion, hematoma, and so on.

Injury severity is defined as the extent of physical trauma to the accident victim, and, depending on the injury type, may have a wide range of possible descriptions. 
A morbidity parameter is a quantitative description of the injury severity, where such descriptions are meaningful and practicable in a medical or analytical context. Examples would be an amount of certain radiation per unit area of exposure or a diagnosis as a set of specified morbidity parameters.

Product involvement is essentially the way in which a product contributes to an accident and any subsequent injuries.

Each of these factors plays a critical role in our analytic procedure. They will be used to develop qualitative criteria for generic properties of product-hazard characteristics. In the material to follow in Section C, two modifiers are associated with each of these factors. These modifiers are used to identify the extent of the factor in the accident phenomena. For each of the terms "injury type" and "injury severity," we specify whether the factor has a narrow or wide range of effects. For the "morbidity parameter" we specify whether the trauma is describable by a single parameter or by multiple parameters of physical damage; and for "product involvement" we specify whether the mechanism by which an injury is produced can or cannot be described in general terms for all products which produce the injury. If it can be stated that an injury of a particular type and severity can be generically associated with a product-type or a class of products, then we use the term independent when referring to product involvement. If it cannot be stated as independent, then the product involvement cannot be described generically at the product-type or class level, i.e., we lose the ability to describe the effects generically. In this case the term dependent is used in referring to product involvement. 
Although narrow and wide are qualitative modifiers, it is intended that "One or few" is implicel when using narrow, and "several or many" is implicel when using wide. In the context of the analysis of Section C below, these terms will assume meaning relative to the problem under investigation. For a specific problem, the analyst will know, or determine by repeated application of fault-tree analysis, empirical evaluation, or testing, how many is implied by the modifier narrow and how wide the range of effects will be. The values for these modifiers will determine, to a large degree, the likelihood of using a generic regulation.

By attaching modifiers to each of the factors a number of combinations are created, each of which has its own characteristics and consequences as it relates to countermeasures. With four factors and a choice of two modifiers for each factor, sixteen combinations are possible. Section B, below, enumerates these combinations and discusses the consequences of each.

\section{B. Combinations of Principal Factors}

The four factors and their modifiers are presented as combinations in Table II-1. At the top of the table the four factors are given, and in the right-hand colum a comment is provided about the regulatory form best suited for each combination. In the table, let $\mathrm{N} \equiv$ narrow, $\mathrm{W} \equiv$ wide, $\mathrm{S} \equiv$ single, $\mathrm{M} \equiv$ multiple, $\mathrm{I} \equiv$ independent, $\mathrm{D} \equiv$ dependent, stand for the modifiers.

Of these sixteen combinations, one ( $\# 2$ 2) seems ideally suited to generic formulation, and three others (\#4,8,12) suited to generic formulation, if the complexity of multiple test methods does not defeat the advantages of generic control. Most of the combinations appear to result in situations which may require product-specific regulation. If this is true, 
Table II-1: Array of Combinations of Principal Factors

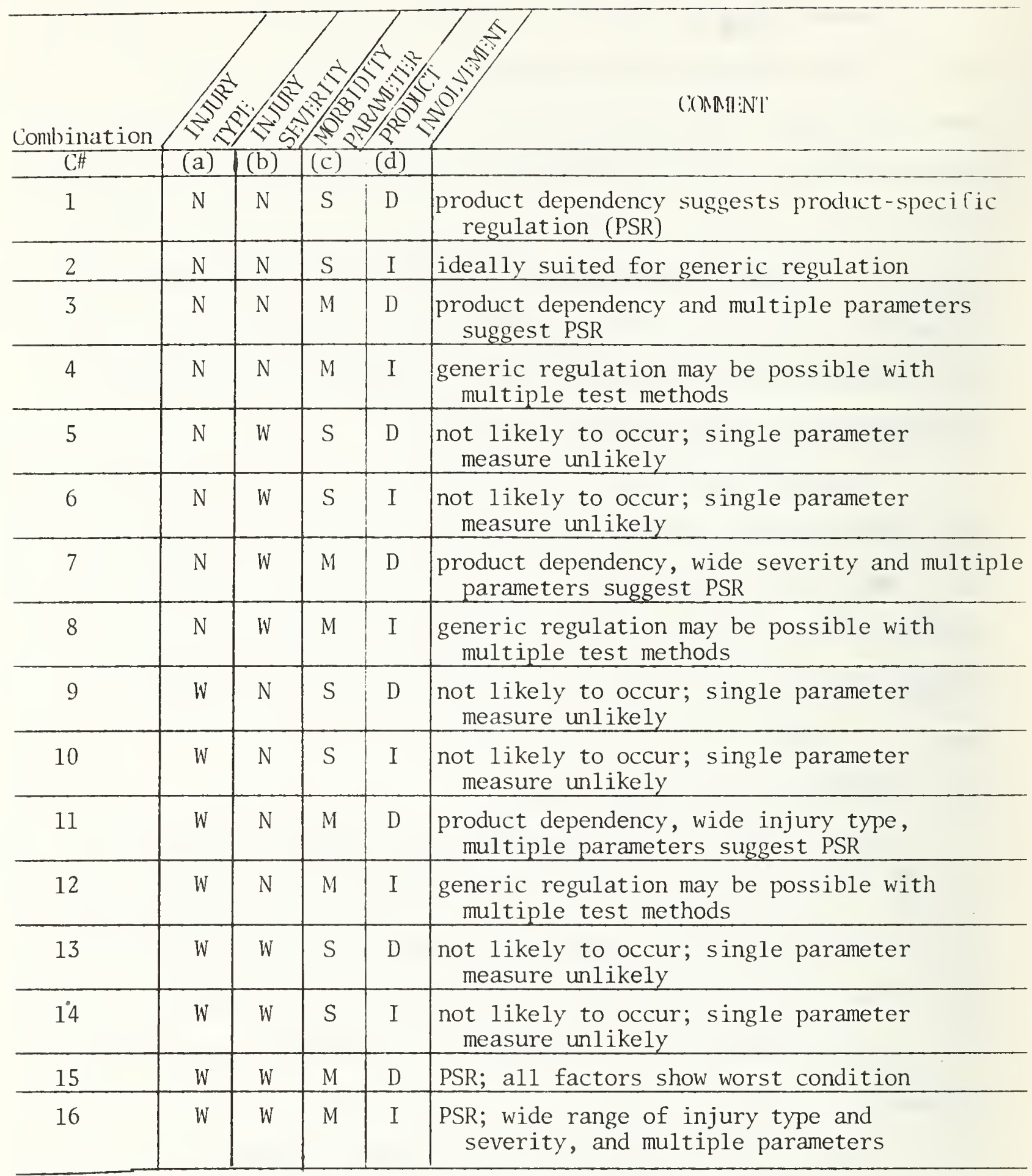

Legend:
$\mathrm{N} \equiv$ narrow
$\mathrm{M} \equiv$ multiple
$W \equiv$ ride
$I \equiv$ independent
$\mathrm{S} \equiv$ single
$\mathrm{D} \equiv$ dependent
PSR $\equiv$ product-specific regulation 
however, for a particular product-hazard problem will depend on the nature of the injury type and severity, and the extent to which a proposed countenucasure is dependent on product chandeteristics.

Sections C and D, which follow, present a procedure and data sources for resolving these issues f.r a particular problem. They indicate also which methods are needed to develop information for making decisions in each phase of the investigation.

C. Procedure for the Determination of the Generic Case

In the analysis of product-hazard regulation there are three major issues to address: the injury mechanism, the control of that mechanism, and the test method. Figure II-1 displays a procedure for analyzing and evaluating these issues. Information about countermeasures, test method and the injury mechanism is a1so generated as a result of this analysis.

Our approach is to use the logic displayed in Figure II-1 as a basis for a stepwise procedure of evaluations. A procedure follows in which each step includes comments concerning methods and data sources appropriate to the operations of that step.

Procedure:

STEP I: The first task is to develop the product-hazard cluster. This development is based on identifying a particular set of products, or product-types, that are directly associated with the occurrence of a certain hazard. Assigning products initially to the cluster is based on statistical evidence and a fault-tree analysis* of suspected product-types. The data

\footnotetext{
*The elements of fault-tree analysis are given in the appendix.
} 


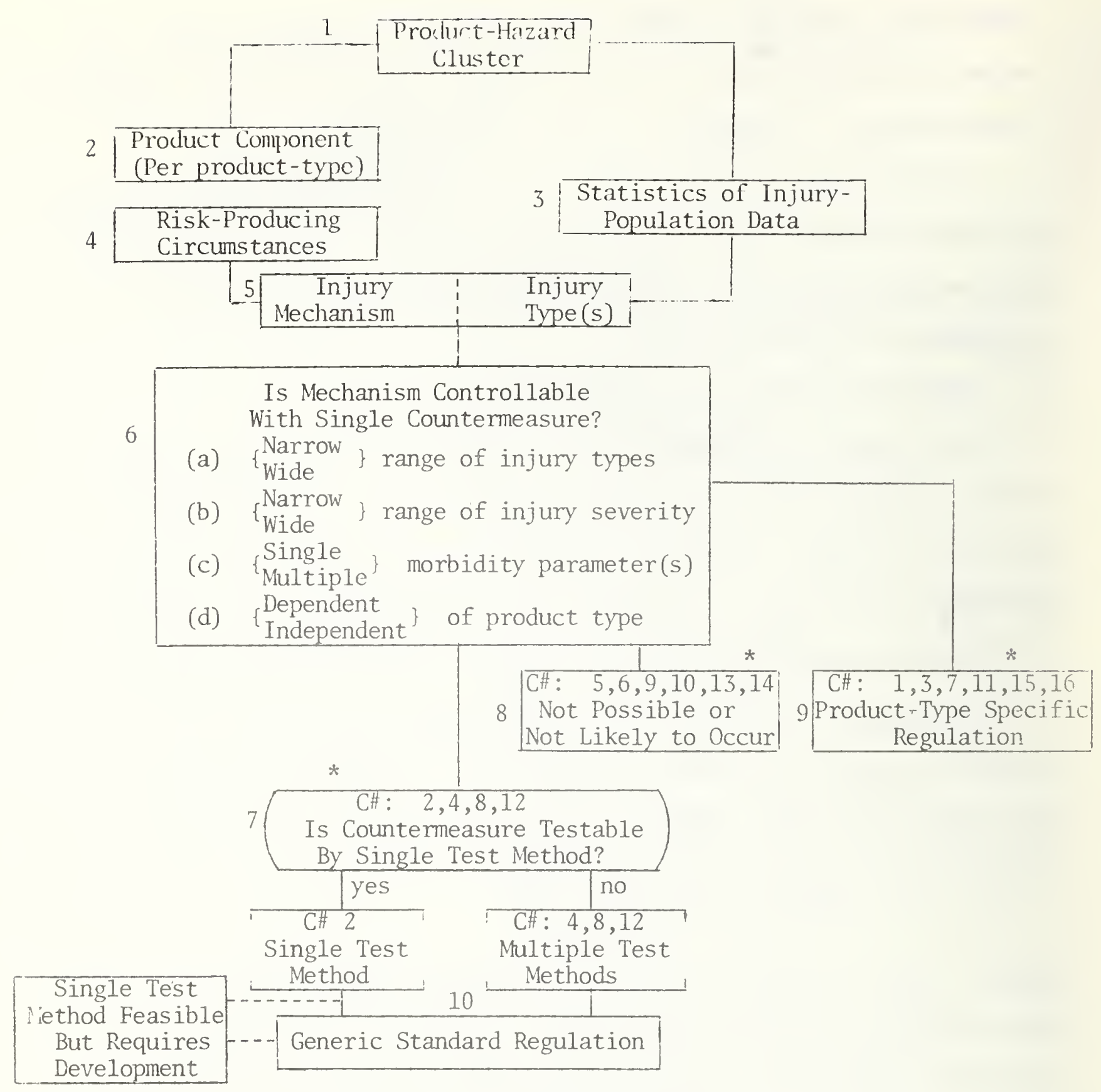

*The numbers referred to correspond to the combination numbers in Table II-1.

Figure II-1: Flow Chart of Analytic Procedure 
sources for this step are statistical compilations, in-depth reports and product-type descriptions. It my occur that the cluster is too small for further consideration for generic control. This decision is left to the analyst.

STEP II: Analyze the product component and risk-producing circumstances (Boxes 2 and 4 of Figure II-1). The analyst should develop a precise description of the manner in which the product component is involved in the hazard. The risk (degree of hazard control) and the accident sequence should be described in specific detail. This information is obtained from descriptions of product components and an engineering study, or other evaluation, of the risk-producing circumstance. The use of a fault-tree analysis will be of great assistance in providing the needed details. The analyses of this step and Step III are used in Step IV. STEP III: Develop from accident frequency data, population demographics, and injury severity data, the range of injury severity and descriptors of injury types. The intent of this step is to characterize the number of injury types by population classes which are associated with a producthazard cluster and to determine the morbidity parameters associated with the types of injury (Box 3 of Figure II-1).

STEP IV: Use fault-tree analysis to determine the causes and contributing factors or events in the injury-producing mechanism; obtain a specific description of injury type(s) and population affected. The results of this step should provide preliminary information about the injury mechanism and what form its control may take. This step may require a "boot-strap" operation to get started. The analyst should postulate the injury-mechanism and then refine its description and character with repeated evaluations of data, fault-tree analysis and product attributes. 
STEP V: Ascertain those countermeasures which can be used to correct the perceived product-hazard problem. This determination is based on the evaluation of four conditions:

(1) the number and character of injury types,

(2) the number and character of injury severities,

(3) the number of morbidity parameters needed to characterize the injury severities,

(4) the relationship between the countermeasures and product-type(s). Table II-1 enumerates the possible combinations of these four conditions, based on an understanding of narrow as few and wide as many. Just how "few" and how "many" must be determined by the analyst. This decision is based on his perception of the degree of generality he is willing to accept as a basis for generic regulation. For an effective generic standard, "narrow" should be no more than two, and "wide" should be greater than two. Otherwise, either the problem can be treated by separating the effects and analyzing them on that premise or the problem is not likely amenable to generic regulation.

Box 6 of Figure II-1 shows the sixteen combinations of Table II-1. A study of Table II-1 reveals that three groups emerge, the first with generic possibilities (Box 7), the second with little likelihood of occurrence (Box 8), and the third for which a product-specific approach seems to be more appropriate than a generic one (Box 9). The numbers shown in Boxes 7, 8, and 9 refer to the combinations of Table II-1. It should be noted that for a particular problem these conclusions, as represented by the comments with Table II-1 and the logic of Figure II-1, may be different in some degree, and such differences might lead to modifications of our general conclusion about these combinations and 
their generic properties. Boxes 8 and 9 are not developed further, since they show that either the combination is unlikely or the combination appears to be better suited for product-specific regulation. Box 7 is the next step of our analysis which addresses the resolution of issues concerning test methods.

STEP VI: Determine whether a single test method can be specified. It is necessary to use information on the injury mechanism, product components, and the number of and differences among the identified morbidity parameters (ref. Step III). A suggested method for addressing these issues is to use the fault-tree approach. When fully developed, it provides an appropriate level of detail about matters concerning testing and countermeasures. As a result of this evaluation we expect either a generic standard to emerge with a single test method (C\#2) or a generic standard with several test methods (C\#4, 8, 12).

Step VI might reveal that a test method can be specified, but may not be readily available in a current standard. The analyst should consider developing the test method for the generic standard if it is feasible to do so. Further, if test requirements can be grouped into a single set of specifications, or if several test methods can be replaced by a single test method, then a single test method should be considered.

We summarize in Table II-2, below, the data sources and methods of analysis which may be utilized in the steps of an investigative procedure. To a large degree the problem under study will determine which methods, data sources, etc., will be used. Table II-2 is only intended as a general guide and reminder for the analyst. The table includes several methods which are not described in the text: rank-ordering by value, rank-ordering by index, correlation analysis, and factor analysis. II -9 
These techniques are conceptually difficult and require a familiarity with advanced statistical methods to be used effectively; they also require detailed data structures in order to perform between-cluster and withincluster analyses. Their inclusion in Table II-2 is for completeness and to remind the user of their existence in the case that fault-tree analysis is inadequate but appropriate data sources are available. Professional assistance should be obtained if these methods are employed.

T.ble II-2: Suimary of Methods and Data Sources

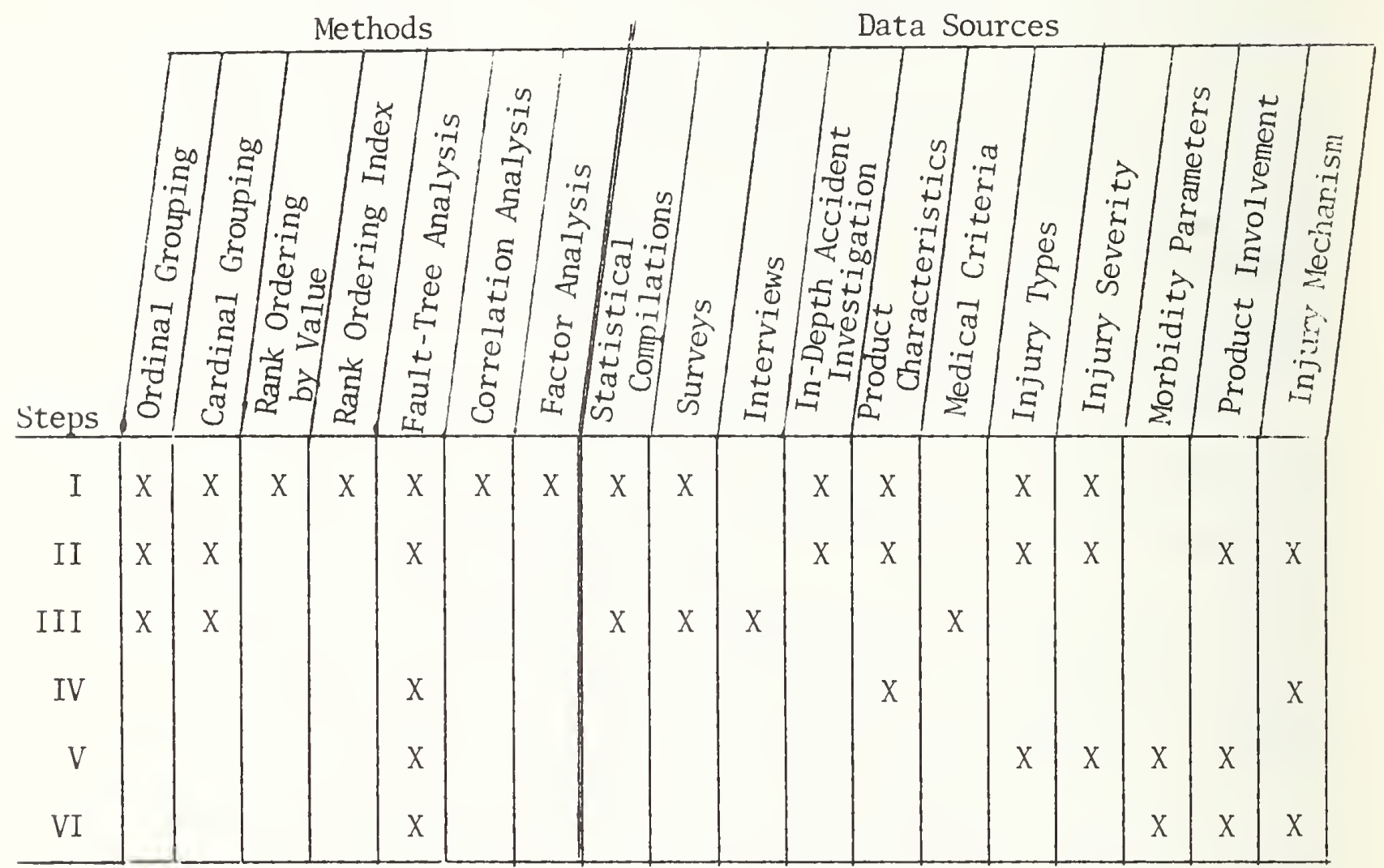

D. Method of Analysis

Introduction

Sections A, B, C, above, describe the process by which the generic case is identified and analyzed. In this section the details of the 
analysis are developed. These details address the classifications of injury, injury severity, products, and hazard. The classifications provide the basis for determining the commonality of the hazard among the producttypes, establish that product-types are correctly evaluated, and determine appropriate countermeasures and test-method characteristics. Further, these classifications are intended to be used in conjunction with and provide input to a fault-tree analysis. The fault-tree method provides an opportunity for obtaining a number of additional insights (see Appendix) above and beyond the primary objectives of identifying countermeasures and test-methods.

1. Injury Severity Analysis and Classification

\subsection{Injury Types}

There are three levels at which injury types may be organized. The first, and most general, employs broad classification descriptors such as toxicity, shock, pressure, burns, and mechanical. Within this scheme each of these descriptors may be subdivided into more detailed descriptors which denote the sources of injury, such as noise under the descriptor, pressure.

The second level uses medical descriptors which depict the injury as a type of diagnosis. Examples of this classification are fracture, dislocation, concussion, laceration, hematoma, and so on. The number of such descriptors would be adapted to the injury types associated with the product-hazard combinations under study. Presumably, these would be very few in number, but it is important to capture in the classification plan any wide variation of hazard-injury combinations which may be present. 
The third level combines the medical descriptors of the second level with descriptors which specify body-parts and appropriate characteristics of the affected population, such as age, sex, and environment.

To determine whether the hazard is generic or product-specific, the third leve1 of injury-type classification will probably have to be used; the first or second levels may not provide sufficient resolution to determine the issue for or against a generic approach. It is important also to have a scheme in which accident data may be organized to display distributional characteristics. If multivariate analysis is to be done, particularly factor analysis, then a classification scheme at the third leve1 is required.

\subsection{Tabulations of Product-Severity Data}

A great deal can be learned about product-severity relationships from tabulations of accident data when arrayed in particular ways. Figures II-2A and II-2B show dummy matrices of two possible organizations of data.

Figure II-2A: Severity Tabulation Matrix

\begin{tabular}{|c|c|c|c|c|c|}
\hline & & & & ${ }_{\mathrm{B}}$ & \\
\hline \multirow{2}{*}{$\begin{array}{l}\text { Disposition } \\
\text { of Patient }\end{array}$} & \multicolumn{5}{|c|}{ Severity Class } \\
\hline & $\mathrm{A}$ & $\bar{B}$ & $\mathrm{C}$ & $\mathrm{D}$ & $\bar{E}$ \\
\hline \multicolumn{6}{|l|}{1} \\
\hline \multicolumn{6}{|l|}{2} \\
\hline \multicolumn{6}{|l|}{3} \\
\hline \multicolumn{6}{|l|}{4} \\
\hline 5 & & & & & \\
\hline
\end{tabular}


Figure II-2B: Severity Tabulation Matrix

\begin{tabular}{|c|c|c|c|c|c|c|}
\hline \multirow{3}{*}{\multicolumn{2}{|c|}{ Body Part }} & \multicolumn{5}{|c|}{$\begin{array}{l}\text { Product-Type Code No.: XYZ } \\
\text { Diagnosis: Thermal Burn } \\
\text { Population Group: }\end{array}$} \\
\hline & & \multicolumn{5}{|c|}{ Severity Class } \\
\hline & & A & $\mathrm{B}$ & $\mathrm{C}$ & I & E \\
\hline & 1 & & & & & \\
\hline & 2 & & & & & \\
\hline & 3 & & & & & \\
\hline & 4 & & & & & \\
\hline & 5 & & & & & \\
\hline & - & & & & & \\
\hline & & & & & & \\
\hline
\end{tabular}

These tabulations will show the general relationships among variables of interest, and can be used to develop input data for any of the evaluation methods in these guidelines. A composite of such tables provides a picture of product clusters in regard to diagnosis, severity and body part as they relate to product-type.

1.3. Injury Severity and the CPSA

Section 9(c)(1) of the Consuner Product Safety Act states, in part, that prior to promulgating a consumer product safety rule, the Commission shall make appropriate findings for inclusion in such rule with respect to--

(a) The degree and nature of the risk of injury the rule is designed to eliminate or reduce; and

(b) The approximate number of consumer products, or types, or classes thereof, subject to such rule. 
It is clear that these words imply (1) a requirement to depict the hazard and its countermeasure, and (2) an estimate of the impact of a rule on a class of product-types, or on separate products. Severity is the critical variable in the development of a countermeasure or evaluating a rule's impact. Consequently, in the identification and presentation of severity data, characteristics and consequences are both central to and technically requisite for the development of a standard.

2. Product Characteristics

Introduction

We now examine ways in which product characteristics can be structured for purposes of analysis and evaluation. Although a standard usually addresses a product's performance, it is important to emphasize that all aspects of a product's history, from design to distribution and use, should be considered when identifying hazard and determining corrective measures for perceived risks.

Our interest in products ranges over three broad areas: involvement in the dynamics of the accident, safety requirements, and functional performance. Our evaluation of these areas is based on "scoring" a product or product-type by filling in a matrix of interacting factors.

2.1. Product Involvement

Figure II-3 is a scoring layout for depicting the nature of a product's involvement in an accident sequence. The information on which scores or groupings are made may be derived from in-depth accident reports, special studies, interviews, and fault-tree analysis. Scoring product involvement may be done either by checking a characteristic 
according to the interaction or by assigning a number which represents the importance of the interaction. The "checking" method serves only to alert the user of a problem, whereas "assigning a number" serves to represent the severity of a problem. It may not be possible to score a product properly until a fault-tree study is made or an engineering evaluation of the interaction is performed.

Figure II-3: Product Involvement Scoring Matrix

\begin{tabular}{|c|c|c|c|c|c|}
\hline \multirow[b]{3}{*}{ Product Characteristics } & \multicolumn{5}{|c|}{ Interaction Modes } \\
\hline & \multicolumn{3}{|c|}{ Consumer Use } & \multicolumn{2}{|c|}{ Environmental } \\
\hline & Normal & Abnormal & Stress & Norma1 & Abnorma1 \\
\hline \multicolumn{6}{|l|}{ Design } \\
\hline \multicolumn{6}{|l|}{ Construction } \\
\hline \multicolumn{6}{|l|}{ Materials } \\
\hline \multicolumn{6}{|l|}{ Components } \\
\hline \multicolumn{6}{|l|}{ Performance } \\
\hline \multicolumn{6}{|l|}{ Deterioration } \\
\hline Total Score & & & & & \\
\hline
\end{tabular}

The analyst should adapt the number or detail of these characteristics and the interaction modes as appropriate. Whatever scores are used should be consistent for a11 three phases of the product investigation.

2.2. Product Safety Requirements

Figure II-4 is a scoring matrix for evaluating a product's safety characteristics. Each product is graded with regard to its safety features for the user; degree of compliance with safety standards; and for the safety of product components, where those components may involve a potential hazard if controls deteriorate, are absent, or are inadequate. 
Figure II-4: Product Safety Scoring Matrix

\begin{tabular}{|l|l|l|l|}
\cline { 2 - 4 } \multicolumn{1}{c|}{} & \multicolumn{2}{|c|}{ Safety Features } & \\
\cline { 2 - 4 } Product Characteristics & User & Product Components & Compliance \\
Construction & & & \\
Strength & & & \\
Energy Source & & & \\
Thermal Conditions & & & \\
Noise & & & \\
Vibrations & & & \\
Edges & & \\
Spacing & & \\
Stability & & \\
Surfaces & & & \\
Mechanical Action & & & \\
\hline Total Score & & & \\
\hline
\end{tabular}

As before, this scoring matrix may need to be adapted for a specific problem; it is assumed the analyst can make the necessary changes in the scoring matrix to suit his needs.

2.3. Product Functional Performance

Figure II-5 is a scoring matrix for evaluating a product's functional performance. Each product is rated on its engineering and physical properties. We wish to determine how the product responds to 
conditions which may create a hazardous condition, an unsafe substance, or a dangerous energy potential. The score should reflect the presence of controls as they appear in the make-up of the product's configuration. As before, it may be necessary to perform an engineering evaluation before a score can be assigned.

Figure II-5: Product Functional Performance Scoring Matrix

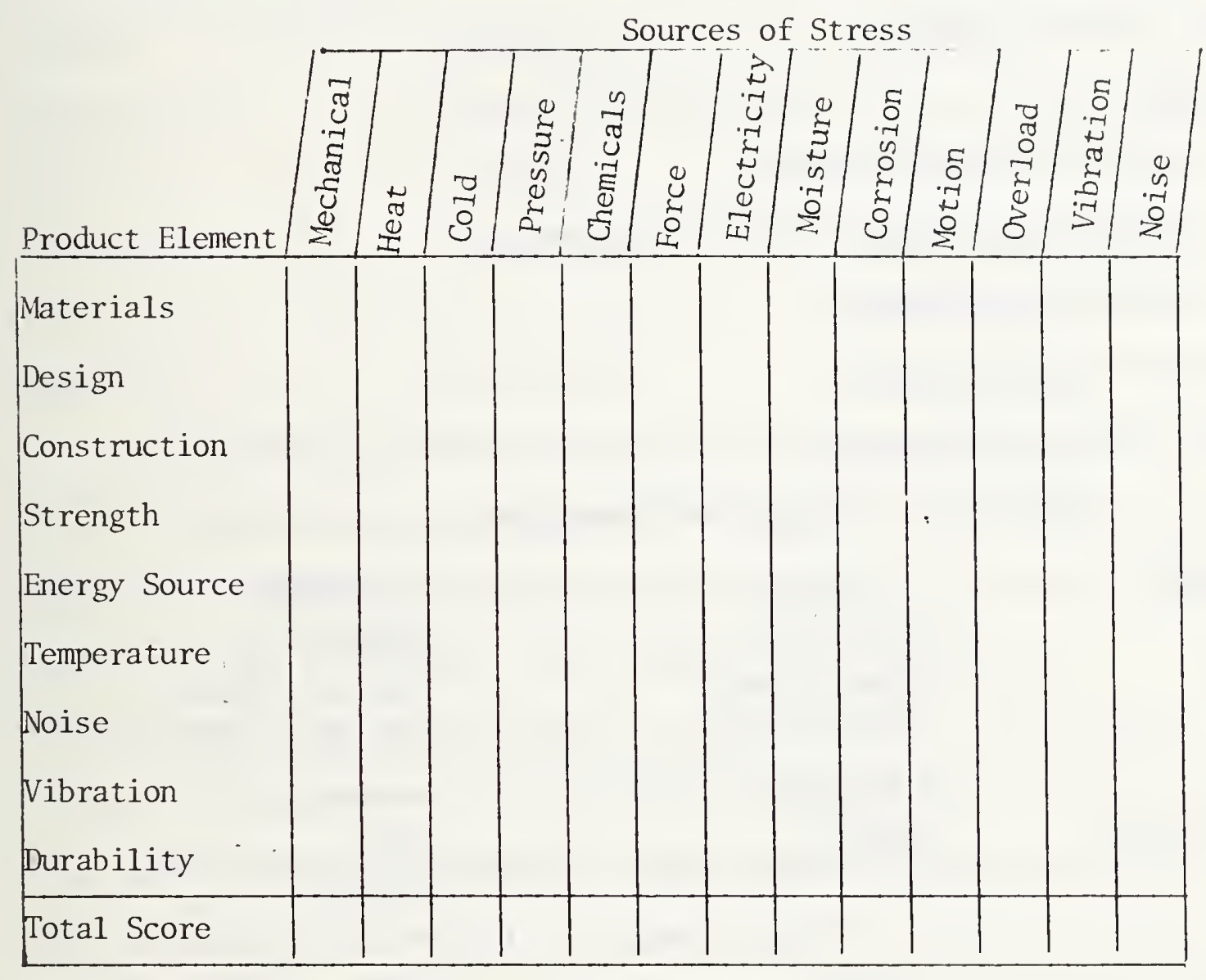

3. Classification of Hazard

The primary reason for classifying hazards is to distinguish those characteristics of the hazard which determine whether a generic standard is possible. It is essential to study carefully all aspects of the 
product-hazard and hazard-injury phenomena in order to separate or resolve hazards which appear to be similar. This analysis provides the basis for specifying appropriate countermeasures. It is equally essential to identify the range of variation a hazard may have because it is critical to determining whether a condition is correctable by a generic regulation.

A hazard should be classified according to the manner in which it is associated with the following:

1. type,

2. factors in Hazard Creation,

3. primary and Secondary Sources of Hazard,

4. hazard Manifestations.

These are now discussed in turn.

Hazard Type may be described by the following table* of descriptors: Table II-3: Hazard Type Classifiers

Mechanical
Cut
Puncture
Bruise
Fracture
Particle in Eye

Shock

Electrical

Pressure

Contact

Physiological

Trauma

Cold Inmersion

$\quad$ Burn
Electrical
Thermal, heat
Thermal, cold
Radiation
Chemical

Toxicity

Asphyxiation

Organic Damage

Respiratory System

Circulatory System

Dermatosis

\author{
Pressure \\ Acceleration \\ Crushing, fluid \\ Crushing, solid \\ Pinching \\ Noise \\ Vibration
}

*Hammer, W. , "Handbook of System and Product Safety," Prentice-Ha11,
1972, Chapter 4. II -18 
Fault-tree analysis is recommended for classifying factors that create or contribute to the hazard. This analysis identifies how the factors involve the characteristics of the product, its mode of use, and the ability of the user to abuse the product. We specify these possibilities in Table II-4.

Table II-4: Classification of Factors in Hazard Creation

$\begin{array}{llll}\text { Product Characteristics } & \text { Product Safety Control } & \text { Product Performance } \\ \text { Design } & \text { Materials } & \text { Materials } \\ \text { Construction } & \text { Design \& Construction } & \text { Design \& Construction } \\ \text { Materials } & \text { Strength } & \text { Strength } \\ \text { Performance } & \text { Energy Supply } & \text { Convenience Factors } \\ \text { Durability } & \text { Hazard Type } & \text { Normal Mode } \\ \text { Components } & \text { Reliability } & \text { Abnormal Mode }\end{array}$

The identification of primary and secondary sources of hazard provides information about the combination of events and conditions which contribute to the creation of a hazard. This information is required for establishing the nature and scope of a countermeasure to the hazard. If the countermeasure is directed toward modifying hazard sources rather than hazard control, then both the countermeasure and the test method may be product-type dependent. The generic case is lost if the hazard sources are different for each product-type. A better opportunity for generic control is obtained if the countermeasure and test method are directed toward hazard control.

Hazard manifestation refers to the nature of an accident and any subsequent injury, but it may also be important to consider how it relates to product durability, reliability and non-consumer safety problems. 
All possible modes, variations and forms of the hazard should be ascertained. If the hazard is capable of creating other hazards, or displays itself in varying degrees of severity depending upon conditions, then each manifestation may have to be treated separately. Countermeasures designed against the hazard source may be totally different from countermeasures designed to control the manifestations of the hazard.

The best method for analyzing these conditions appears to be the fault-tree diagram, supported by engineering evaluations of the product in scenarios which cover appropriate user-product modes.

4. Method of Analysis

Given that the classifications of injury and severity, product involvement, and hazard have been carried out, our investigation is ready for the next step: to develop the product-hazard combinations and assign these combinations to groups or clusters according to some criteria.

Figure II-6 presents a procedural diagram. The formation of producthazard combinations is based on bringing together the classifications of injury and severity with product involvement. The specification of the countermeasure and the characteristics of the test method are developed from the attributes of the product-hazard combinations in the cluster. The critical aspects of this process are the assignment criteria and the identification of the countermeasure.

4.1. Assignment Criteria

The assignment of product-types to a cluster is based on five broad criteria:

1. hazard characteristics and intensity,

2. product component, 


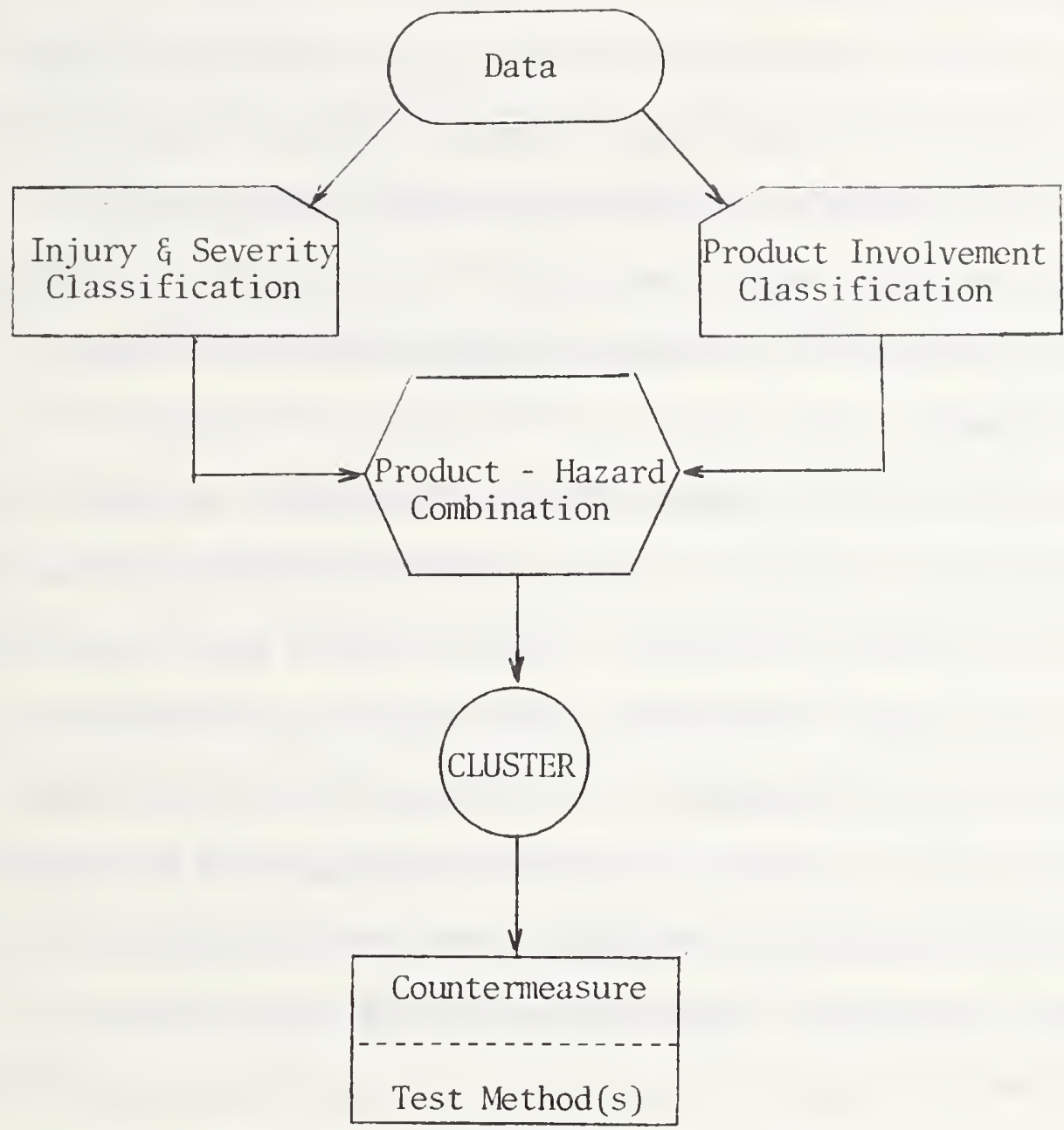

Figure II-6: Generic Standard Development 
3. physical injury mechanism,

4. population affected,

5. human factor level.

The criterion of hazard characteristics and intensity deals with the injury type, severity and range of physical effects associated with the hazard. This criterion establishes the basic attribute of the cluster and the product-hazard combinations. The remaining four criteria determine the differences or similarities among products and their ultimate assignment.

The second criterion, product component, determines the extent to which products have components in common which are associated either with the hazard or the process of injury. It may be that a given regulation can be made for a cluster of products even if there are differences in their hazard-associated components. This situation could arise from a safety problem which is primarily related to performance or the injury mechanism rather than product components. This criterion may serve as an independent test or as a subsidiary test of the third criterion.

The mechanism by which the injury occurs is the third criterion, and we are concerned here with the mechanical aspects of product involvement, the forces applied, and the dynamics of the user-forces-product components mix. The recommended method for evaluating the product-hazard combination for this criterion is fault-tree analysis, which should provide the necessary description of the accident scenario. We discuss below the need to evaluate carefully any proposed countermeasure against the details of the accident scenario and to ascertain the capability of the countermeasure to control the injury mechanism of each product in the cluster. 
The fourth criterion, population affected, is intended to distinguish products, if it is critical to do so, on the basis of the age or sex, or on some other demographic variables, of the population experiencing the accident.

The fifth criterion, human factor level, distinguishes those producthazard combinations in which the injury mechanism is primarily caused by an act or motion of the user. This criterion attempts to separate the primarily human factors accident from the primarily mechanically produced accident. The appropriate countermeasure for the former is more difficult to specify than the countermeasure for the latter, and is likely to address the interaction of the user with the product. In the latter case, however, the countermeasure assumes that human activity is not a significant contributor to the accident, and therefore addresses a product component or mechanism. There is a middle ground in which a countermeasure may have to address some aspect of human activity in its control of the product. How these interactions affect the assignment of a product to a cluster depend on the product-hazard combination being investigated.

4.2. Identifying the Countermeasure

At this point in the analysis, product-types are assumed to be assigned a cluster, and the cluster is characterized by the common attributes of its members. The next step is to define a single countermeasure for all the products in the cluster and determine that the countermeasure is applicable to each product in the cluster. 
The countermeasure will be more effective if it can address the injury-mechanism directly. If the injury-mechanism involves a complex sequence of interactions and human activities, the countermeasure may be limited to an indirect control of the hazard. If this occurs, a deeper examination of a fault-tree analysis may be necessary to identify those conditions for which direct control can be established. If this cannot be easily done, it may be necessary to use the injury-mechanism criterion a second time to separate products in a cluster into two groups, one amenable to the specification of a countermeasure and the other for which control cannot be isolated and addressed by a countermeasure.

When the countermeasure has been established, each product should be examined in the light of the countermeasure to determine whether there is any condition or situation not covered or addressed by the countermeasure, and whether the statement of the control is ambiguous with regard to individual products. This process of checking the injury-mechanism of each product against the countermeasure, and verifying that the productcountermeasure relation is correct, is a necessary fine-tuning and should be iterated until as many products as possible are adequately and effectively covered by the final definition of the countermeasure.

4.3. Characterizing the Test Method

A test method is usually a specified procedure which uses test equipment, data, criteria, and instructions to determine product compliance to a standard. The test method may address safety, or some aspect of product reliability and durability.

A test method for a generic safety standard depends directly on the specifications of the countermeasure. The countermeasure must be defined 
in technical terms and must specify all conditions to be satisfied. The basis for a test method is established when the countermeasure is presented as a technical requirement. Since the test method is intended for a large number of product-types, it is likely that it will have to be developed directly from the specifications of the countermeasure; but it may also be possible to customize a satisfactory test method by using appropriate parts of existing standards.

The problem of multiple test methods arises for those situations in which the technical requirements of the countermeasure cannot be fulfilled by a single test method, or one in which the product-types are such that a test method is needed for groups of types, even though a single countermeasure is in effect.

This latter situation may be simplified by splitting a generic standard with multiple test methods into separate standards; but this will depend on the relative efficiencies of the multiple version versus the single. It is not a requirement of a generic standard that it must have only one test method; however, this is the ideal case.

\section{E. Summary}

Chapter II has developed the concepts given in Chapter I into a method of analysis which provides the basis for developing a generic safety standard. The salient points of this method are the classification of the product and injury data, the extensive use of the fault-tree diagram, and the iterative process of evolving the specifications of the countermeasure. The essential portion of the process, on which hangs the success or failure of the effort, is the development of the cluster, whose properties are those of its members. The degree to which these 
properties are different or similar with regard to the product and the hazard determine whether a universal countermeasure and test method can be obtained.

A determined application of the assignment criteria and the faulttree analysis should provide a tool of adequate sophistication for most problems of generic standards development, but judgment is a necessary part of making the scientific analysis work effectively. 
Int roduction

With the results of the investigative procedure of Chapter II

in hand, we are now ready to prepare the generic standard as a formal instrument for review and evaluation. The documentation should include an exposition of the product characteristics to be modified, the hazard to be controlled, the countermeasures to be imposed, and the manner in which the test method will apply.

A. Product Characteristics Modified by Generic Standard

A11 aspects of the modification of the product or product-type should be clearly detailed in both qualitative and technical terms. It is important to know how the characteristics of any product change so that an evaluation can be made concerning the impact on performance, efficiency and cost of the modified product. The direct and indirect consequences of the countermeasure should be explained, and any assumptions or latent conditions clearly stated.

B. Hazard Characteristics Controlled by Generic Standard

All aspects of the manner and degree in which the countermeasure controls or modifies the hazard must be given. The control should be stated in terms of appropriate scenarios of use and environment, and under what conditions there are exceptions to all or part of the intent of the control. The countermeasure should include, as appropriate, all necessary data or technical descriptions pertinent to evaluating its effectiveness and understanding the way in which it functions as a control. 
C. Countermeasure and Test Methods

Both the countermeasure and the test method(s) should be supported with pertinent technical information for their implementation and understanding. These will include the requirements as imposed by the CPSA, any criteria, exceptions, conditions, test materials, etc. needed for any part of the implementation of the generic standard. The test method will be supported by descriptions and procedures for use, and by threshold criteria for safe product performance. Any needed equipment will be identified for use, whether it is in a laboratory test, or in a test designed for use at the point of fabrication, after production, or after retail. Any impact of the control or test method on any aspect of the normal quality control should be evaluated to determine consequences concerning performance, efficiency or cost.

D. Form of the Standard

The analyst may be able to utilize existing standards, or parts thereof, in the development of the form and content of his generic safety standard. Test methods or descriptive material, either technical or instructional, may be borrowed for inclusion; therefore, the analyst should review all pertinent and appropriate extant standards for sources of material which are directly applicable to the statement of a new generic standard. The analyst should keep in the mind the three forms inclusions may take: the standard may be developed by selecting appropriate sections, or other materials, from parts of other extant standards (eclectic); it may be adapted from an existing standard by modifying a portion or portions of the standard (adaptive); or it may be developed by abstracting portions of other standards and evolve from their incorporation and synthesis (synthetic). 


\section{E. Content of the Standard}

The standard should provide descriptions of the expected product performance; modifications of the construction of the product; test method specifications, use, criteria, data, exceptions, conclusions, test materials, and any special conditions; and any additional features of control above and beyond the principal countermeasure.

F. Generic Standards and the Process of Development

A number of reports and books have appeared recently which deal with various aspects and problems of developing voluntary, product-specific standards. The principal concerns are the effectiveness of the traditional process to produce good standards, motivations for standards development, and the role that standards play in commerce.

These issues are involved and complicated. Standards which address uniformity, quality and interchangeability would be even more complicated if the standard is generic. Since the generic safety standard, as perceived and presented in these guidelines, is directed to the regulation of hazard, there is greater likelihood of a successful development than if the effort addressed the much more difficult problems of uniformity, quality or interchangeability. Addressing safety in a generic way seems less likely to change the traditional development process than a similar effort for one of the more complex aspects of product attributes.

In Chapter I, Section D, seven principal impacts on the traditional process were listed. These will not be repeated here, but the reader should review them as an integral part of the discussion of this section. These seven suggest that the development of a generic.standard requires 
different approaches to data collection, to membership selection, to the business of trade-offs, and to accommodations of the consensus process. The form and extent of the impact will be determined to a large degree by the standard to be developed and the pressures behind the need for the standard. All of the procedures of surveying existing standards, field experience, hazard and injury information now become dependent on distinctions among similarities and differences of the products to be regulated.

The most difficult aspects of the process will be determining the proper membership and representation in the committee for developing the standard, and the ability to achieve a consensus on the standard. However difficult these tasks are, the generic safety standard should have the advantage of being easier to address in context. It may be possible to evolve the standard from revisions of existing standards or to come to quick agreement on the specifications of a generic test method, or methods. The objectives of the standard must be properly perceived by the developing committee, however, and the committee must evaluate the effectiveness of the standard in addressing the safety requirements of the products to be covered. 
Introduction

The effectiveness of a safety standard is measured by the efficiency of its regulation and the degree to which it achieves its principal objective, improved safety. Once a generic standard has been promulgated, however, it may have an immediate and long range impact on the manufacturer, the public and the market.

The following sections point up some of these major areas of impact and suggest how they might be evaluated.

A. Technological Impacts

An area of positive influence is that in which a regulation introduces an improved technological process or in some way enhances a product line in terms of quality or performance. It is also possible that patentable concepts are developed as a result of safety and performance regulation. The analyst, therefore, should be aware of these possibilities by reviewing the industry's response to regulation, studying the application for patents, and observing the technical integrity of new product lines. In the absence of other measures of impact the influence on technology could be an important signal of regulatory influence.

\section{B. Cost-Benefit}

The most direct impacts of a regulation are the cost of compliance and the benefit to the consumer. Conversely, the impact may also provide benefits to the manufacturer and higher costs to the consumer. It follows then that we may have cost and benefits for both the consumer and the manufacturer. The following table attempts to list some of these for both of the 
principal concerned parties. They may not all apply in a particular case but they are potentially present, and are provided more in the nature of a check 1ist.

Table IV-1: Cost-Benefit Array

\begin{tabular}{|c|c|c|c|c|}
\hline & \multicolumn{2}{|c|}{ Consumer } & \multicolumn{2}{|c|}{ Manufacturer } \\
\hline Item & Cost & Benefit & Cost & Benefit \\
\hline $\begin{array}{l}\text { Better product } \\
\text { performance }\end{array}$ & $\begin{array}{l}\text { may be higher } \\
\text { or no change }\end{array}$ & $\begin{array}{l}\text { greater } \\
\text { efficiency }\end{array}$ & $\begin{array}{l}\text { product } \\
\text { modification }\end{array}$ & $\begin{array}{l}\text { more sales, } \\
\text { bigger market }\end{array}$ \\
\hline $\begin{array}{l}\text { Improved } \\
\text { safety }\end{array}$ & $\begin{array}{l}\text { may be higher } \\
\text { or no change }\end{array}$ & $\begin{array}{l}\text { fewer acci- } \\
\text { dents, lower } \\
\text { severity }\end{array}$ & $\begin{array}{l}\text { may be higher } \\
\text { or no change }\end{array}$ & $\begin{array}{l}\text { public acceptance, } \\
\text { enhances } \\
\text { reputation }\end{array}$ \\
\hline $\begin{array}{l}\text { Technological } \\
\text { improvement }\end{array}$ & $\begin{array}{l}\text { may be higher, } \\
\text { lower, or no } \\
\text { change }\end{array}$ & $\begin{array}{l}\text { better effi- } \\
\text { ciency and } \\
\text { performance }\end{array}$ & $\begin{array}{l}\text { may be higher, } \\
\text { lower or no } \\
\text { change }\end{array}$ & $\begin{array}{l}\text { new or enlarged } \\
\text { market }\end{array}$ \\
\hline Compliance & $\begin{array}{l}\text { higher unit } \\
\text { cost }\end{array}$ & $\begin{array}{l}\text { safer } \\
\text { product }\end{array}$ & $\begin{array}{l}\text { testing or } \\
\text { process } \\
\text { modification }\end{array}$ & $\begin{array}{l}\text { public acceptance, } \\
\text { retain market } \\
\text { position }\end{array}$ \\
\hline
\end{tabular}

It may occur that the hazards involve more than just the manufacturer, i.e., improper installation, handling, and so on, in which case the costbenefit equation becomes more complex and difficult to evaluate. It is preferred that the costs and benefits of Table IV-1 be expressed numerically in order to obtain a measurable impact of a regulation on the product, on the manufacturer's technical and financial position, and on public reaction to improved safety and performance. To develop an economic model of these costs and benefits is beyond the scope of these guidelines; the analyst should engage experts in cost-benefit analysis to evolve an appropriate model and its attendant data input requirements. 
C. Estimate of Hazard or Injury Reduction

since the reason for regulation is to provide a specific improvement in the safety of the products it regulates, an estimate of its effectiveness is essential to its evaluation. The various ways in which an estimate can be made fall into two groups: monitoring the population which uses the product, or conducting a technical evaluation in which the estimate is based on a simulation.

The monitoring of the user population can be done by watching the accident statistics for any changes or shifts in product-hazard relationships. Unfortunately, this approach can be easily confused by other factors which may obscure or defeat observing particular changes. This is the problem of the signal-to-noise ratio in observing information. A second problem is the possible long delay before an effect does occur, in which case monitoring is an expensive investment with uncertain results. A second monitoring technique is to perform a "before" and "after" statistical experiment, but here, as above, the problems of signal-to-noise, delayed effects, exogenous variables changing the context of the experiment, tend to discourage the use of this method. A third method is to conduct a study of the movement of products in use and gather data on the effectiveness of the regulation in the context of actual scenarios of productenvironment combinations.

The methods of technical evaluation are an engineering evaluation of the regulated products and a fault-tree analysis of the modified products. The engineering evaluation entails an experimental test of the countermeasure and measuring the product's performance under appropriate and rigorous test conditions. 
The use of a fault-tree analysis as a probabilistic model may provide a reasonably good estimate of effectiveness. If probabilities or weights are assigned to each condition contributing to an injury, then an overall probability or index of occurrence can be computed. If this is done on the product's fault-tree before and after the regulatory control, the difference is a measure of the reduction of the hazard. The principal difficulty is obtaining reliable estimates of probabilities or weights for each process in the fault-tree scheme.

D. Other Factors in Impact Analysis

In addition to the items of the sections above, an evaluation of the impact of a regulation should include an examination of those voluntary standards the regulation is displacing; ascertaining whether or not the scope of the regulation is adequate or weakened by being overextended; evaluating the conditional or compromising effects of assumptions or special conditions; and determining whether the regulation places an unwarranted burden on the process of compliance by virtue of its technical or qualitative requirements. 
APPENDIX

The Elements of Fault-Tree Analys is

A-1 
NNALYTIC STRUCTURI: FOR ILAZARD IVVALUA'TION

Introduction

One of the most effective techniques for identifying and tracing hazard sources is fault-tree analysis. In addition to its main purpose, it also contributes to the development of countermeasures and estimates of risk reduction by virtue of its structure and detail.

The material for this section is based on the excellent text by W. Hammer, ${ }^{1}$ who in turn acknowledges his indebtedness to the basic work on and development of the fault-tree method by the Bell Telephone Laboratories and the Boeing Company. ${ }^{2}$ The concept has been developed by others into an elaborate method of analysis. The full structure of this method is too complex for the purposes of analyzing consumer product hazards, so we have modified the concepts to the needs of our evaluations.

1. Fault-Tree Analysis

The technique of fault-tree analysis is based on the following steps:

1. A description of the hazard under study is set down in terms of its quantitative, operational and qualitative characteristics. If these are incomplete the technique will aid in their discovery.

2. All factors which contribute directly or in combination to the occurrence of the hazard are reviewed. This establishes an initial list of conditions and events needed for the analysis.

\footnotetext{
lHammer, W., "Handbook of System and Product Safety," Prentice-Ha11, 1972 (Chapter 9).

${ }^{2}$ Ibid., page 238.
} 
3. A "tree" is prepared by diagramming contributing events and conditions which show interrelationships to each other and the hazard. The process begins with the events or conditions that could directly cause the hazard. This is the first level of development. As the technique traces back through cause and effect relationships, events and conditions that contribute in some way to the existence of the hazard are added to the tree. As these elements are added, the first level becomes configured with greater detail in the form of branches and nodes, taking on the nature of a "tree" structure.

4. The circumstances under which each element appears in the faulttree are determined. Each portion of the diagram which depicts a sequence capable of producing the hazard is studied carefully to determine in precise terms the nature of its contribution.

5. For each branch of the tree which is determined to contribute directly or indirectly to the hazard, suitable expressions of the interactions of events and conditions are developed in terms of "and" and "or" logic.

6. The probabilities of events and conditions are assigned to each branch, if this information is known. In the evaluation of producthazard combinations the probabilities of occurrence may have to be replaced by a qualitative, judgmental model of the possibilities for certain events and conditions.

7. Interactions are studied or simulated to obtain data on the most critical or likely combination of events and conditions which may occur, 
identifying single point or factor contributions, and identifying all elements which, when modified, could alter the character of the hazard.

Our method is based upon two qualifying conditions:

(1) No operation is partially successful; it either fails or operates properly, and

(2) Basic failures are not necessarily independent of each other.

If two or more basic failures are related, i.e., a subsequent failure or condition is directly traceable to a prior failure or condition, then the diagram of interactions should depict this sequence, even if the model becomes more complicated in its description of such dependent elements.

2. Fault-Tree Logic

In order to develop a fault-tree diagram, certain basic, logical functions have to be provided for, and this is done through the use of conventional symbols which are combined to produce a flow-chart of interactions. The following symbols are based on Hammer.

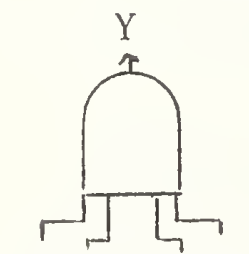

AND gate. Output $Y$ exists if and only if all of $x_{1}, x_{2}, x_{3}, x_{4}$ occur or exist simultaneously.

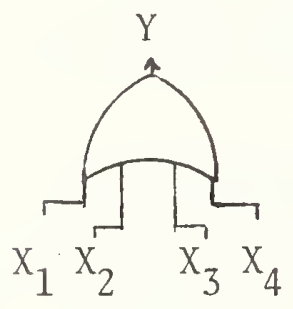

OR gate. Output $\mathrm{Y}$ exists if and only if any one or combination of $x_{1}, x_{2}, x_{3}, x_{4}$ occurs or exists. 

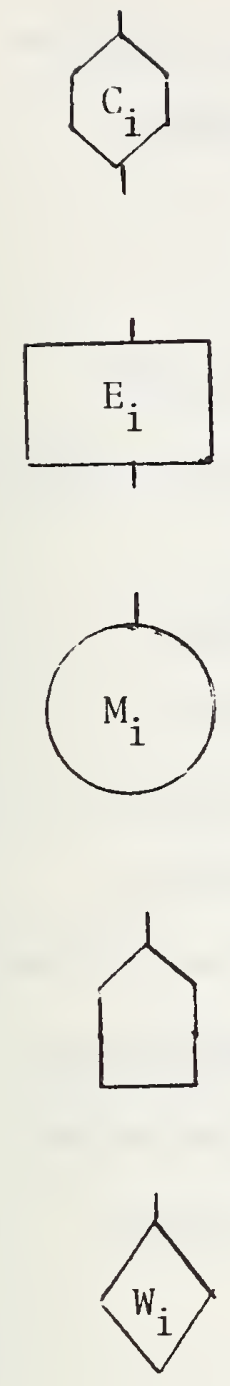

$\mathrm{R}_{\mathrm{i}}$

INHIBIT gate. Permits applying a condition or a restriction. The input and condition or restriction must be satisfied for an output to exist.

Identification of a particular event. As part of a sequence it usually describes an input or output.

An event, usually a malfunction, given in terms of a component of a product or as some combination of conditions.

An event norma1ly expected to occur. Usually always occurs unless affected by a failure or condition.

An event not developed further because of lack of information or of insufficient consequence. Could be used to indicate the need for further study.

Indicates and stipulates restrictions. When used with an AND gate, the restriction must be fulfilled before the event can occur. When used with an OR gate, the event may not occur in the presence of both or all inputs simultaneously. When used with an INHIBIT gate, stipulation is a variable condition. 
A connecting symbol to another part of the tree within the same major branch. Has the same functions, sequence, and numerical values.

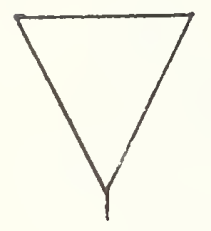

A connecting symbol to another part of the tree within the same major branch. Has the same functions and sequence, but not numerical values.

With these symbols, any simple or complex sequence of events or conditions may be depicted and logically related. Its power is limited only by data which may be incomplete or unreliable, and by interactions which are not conceptually understood or amenable to symbolic representations. Not only does the fault-tree diagram provide a clear characterization of a hazard but it also provides for the identification of primary and secondary factors or elements in the failure sequence, and highlights the specific points at which countermeasures are to be directed.

3. Example of Fault-Tree Diagram

Assume for the example that there is a hypothetical product capable of inflicting a laceration in three different ways. Two ways may occur in normal use and the third only after the product has been damaged. Let the source of the injury be from an exposed sharp edge, a mechanism capable of pinching, and from an exposed ragged edge, a result of the product having an easily broken component. Figure A-1 is a simplified fault-tree diagram of the hazard and its sources. In this figure the OR gates are labeled as $\mathrm{O}_{1}, \mathrm{O}_{2}$, and the AND gates as $A_{1}, A_{2}$, and $A_{3}$. At the top of the diagram is the injury; the injury is 


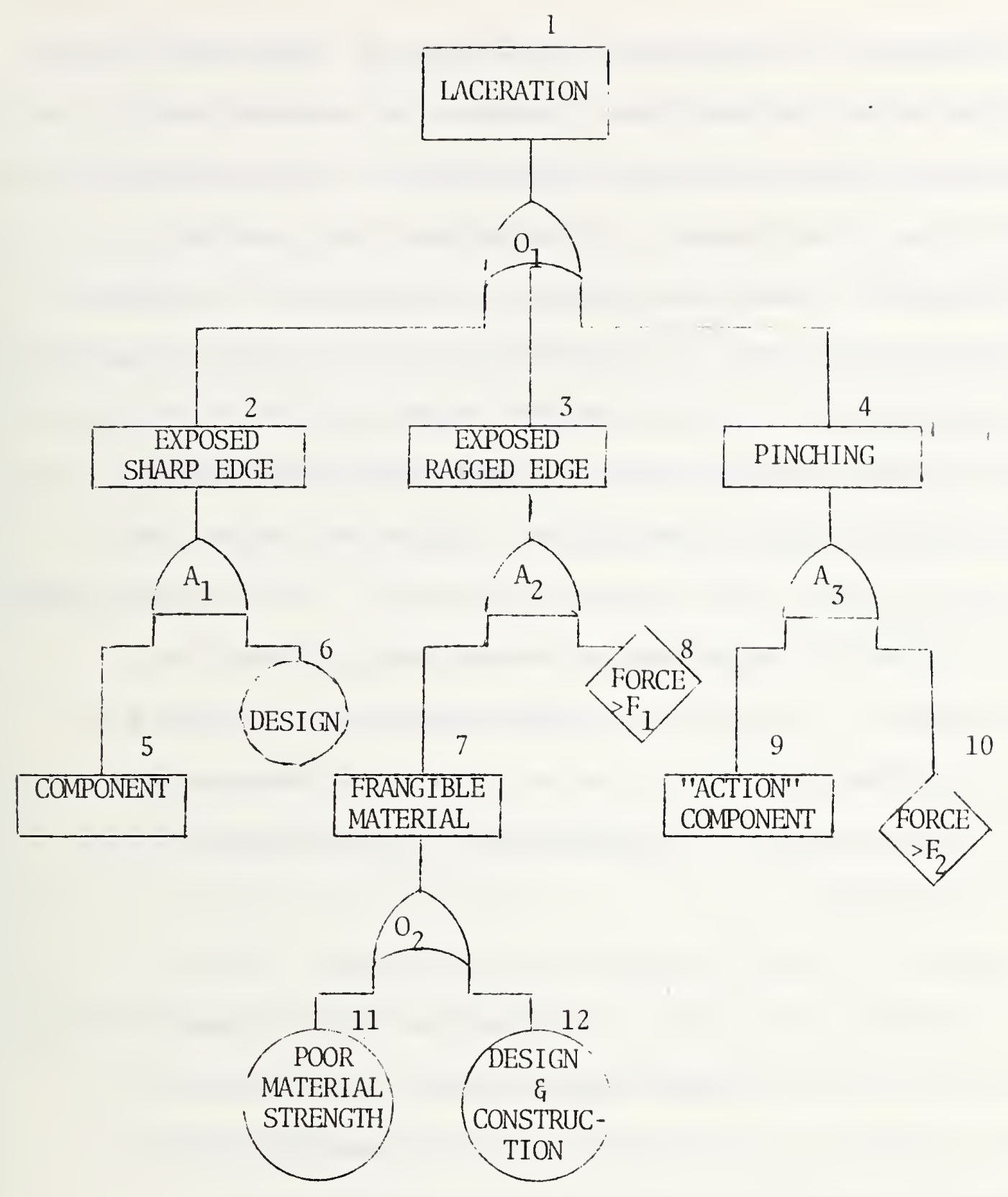

Figure A-1: Example, fault-tree diagram

IOTE: $F_{1}$ is a force level beyond which a breakage occurs and $F_{2}$ is a force level to produce a laceration from mechanical pinching. The elements in circles are indicated as possible sources of malfunction. 
linked to the three possible causes by an OR gate, $O_{1}$. Each cause is then linked to its sources and conditions. A study of this example would indicate that poor design and use of improper material or construction contribute to two of the hazards. If, in the third case, pinching, the action component (element 9 in the fault-tree diagram) is functional, then the countermeasure would be in the form of a safety guard and consumer information about the risk; if the pinching is not associated with the product's legitimate function, then the countermeasure should address the design or construction of the product. The circled elements in the diagram specify elements which represent malfunctions. These interactions may require engineering evaluations in order to depict them in the fault-tree diagram. In such cases the fault-tree analysis will have to wait on this information before it can be completed; it has provided, however, a definite benefit in that the diagram exposed the need for an engineering evaluation.

4. Benefits of Fault-Tree Analysis

In addition to its power as a descriptive tool for product-hazard interactions and depicting product characteristics, fault-tree analysis may provide insight into the comparison of products, energy efficiency, and information needed by the public on product performance.

As a tool for the development of generic safety standards, the method provides a basis for a comparative analysis of product-types if weights or probabilities can be assigned to the interactions depicted by the fault-tree diagram. 
One of the principal assets of fault-tree analysis is its exposure of how well the product-hazard or product-event interactions are understood, described and quantified. If the method does properly portray the actual interactions and conditions, discrepancies or inconsistencies will be apparent in the course of the evaluation of the countermeasure and test-method. These exposures may be of the sort that can be resolved only if an engineering evaluation of the problem is conducted, and therefore the fault-tree analysis will serve to signify these points of ambiguity or misrepresentation.

The areas in which fault-tree analysis provides insight and guidance are:

1. interaction among events or components,

2. exposure and human factors,

3. countermeasures,

4. probabilities or weighted effects,

5. engineering evaluations,

6. product characteristics,

7. analysis of energy use,

8. comparison of products or performance,

9. design changes,

10. consumer information,

11. test method characteristics. 
NBS.I14A IREV.7.7 T)

\begin{tabular}{|c|c|c|}
\hline $\begin{array}{l}\text { U.S. DEPT. OF COMM. } \\
\text { BIBLIOGRAPHIC DATA } \\
\text { SHEET }\end{array}$ & 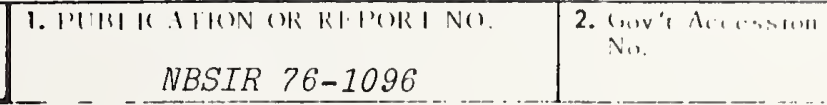 & 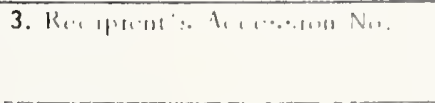 \\
\hline \multirow{2}{*}{ 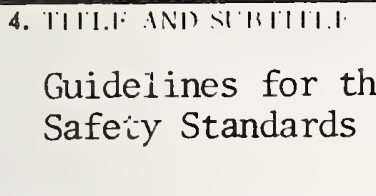 } & \multirow{2}{*}{ Determination and Development of Generic } & $\begin{array}{l}\text { 5. I'ulin asum 1).si. } \\
\text { June } 1976\end{array}$ \\
\hline & & $\begin{array}{l}\text { 6. P'erlorming (1) } \\
\quad 3053\end{array}$ \\
\hline \multicolumn{2}{|c|}{$\begin{array}{l}\text { 7. AUTllor(S) } \\
\text { Roberi G. Hendrickson }\end{array}$} & 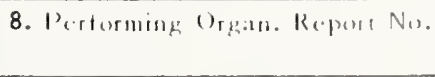 \\
\hline \multicolumn{2}{|c|}{ 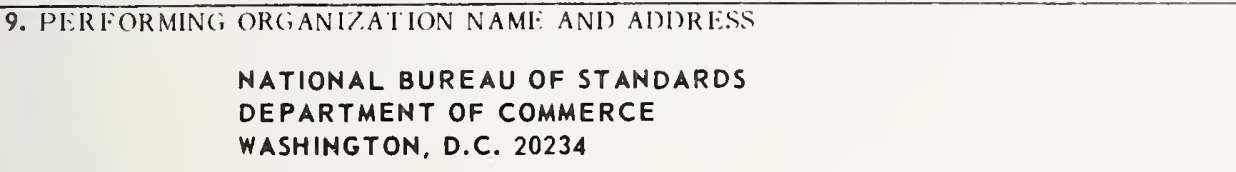 } & $\begin{array}{l}\text { 10. P'ropect/lash Work thit No. } \\
441.1432 \\
\text { 11. Contrace/Cirant } N_{0} \text {. }\end{array}$ \\
\hline \multirow{2}{*}{\multicolumn{2}{|c|}{$\begin{array}{l}\text { 12. Sponsoring Organization Name and Complete Address (Street, Cily, State, ZIP) } \\
\text { Consumer Product Safety Commission } \\
\text { Washington, D.C. } 20207\end{array}$}} & $\begin{array}{l}\text { 13. Type of Report \& Periol } \\
\text { Covered } \\
\text { Final }\end{array}$ \\
\hline & & $\begin{array}{l}\text { 14. Sponsoring Agency c'ode. } \\
118\end{array}$ \\
\hline
\end{tabular}

15. SUPPI.I:MI:NTARY NOTI:S

16. ABSTRAC'T (A 200-word or less factual summary of most significant information. If document ancludess as significant bibliography or literature survey, mention it here.)

'Thes guidelines were prepared to assist the CPSC in the development of generic safety standards. This development is based on conceptual models of product hazard interactions and analyses of accident sequences, product clustering, and hazard characteristics.

The motivation for these guidelines derives from a perceived need to expedite the standard development process and to enhance the efficiency of standards for consumer product safety."

17. KEY WORDS (six to twelve entries; alphabetical order; capitalize only the first letter of the first key word unless a proper name; separated by semicolons)

Operations research - NS Management need

18. AVAILABIL.ITY Unlimited

For Official Distribution. Do Not Release to NTIS

[- Order From Sup. of Doc., U.S. Government Printing Office Washington, D.C. 20402, SD Cat. No. C13

[X Order I'rom National Technical Information Service (NTIS) Springfield, Virginia 22151

\begin{tabular}{|c|c|}
\hline $\begin{array}{l}\text { 19. SECURITY CI.ASS } \\
\text { ('THIS REPURT) }\end{array}$ & 21. NO. OF PAGES \\
\hline UNCL ASSIF IED & 57 \\
\hline $\begin{array}{l}\text { 20. SECURITY CLASS } \\
\text { (TIHS PAGE) }\end{array}$ & 22. Price \\
\hline UNCLASSIFIED & $\$ 4.50$ \\
\hline
\end{tabular}



